$\underline{\text { Review Article }}$

\title{
A REVIEW ON ANTI-AGING PROPERTIES OF PROBIOTICS
}

\author{
BHAGAVATHI SUNDARAM SIVAMARUTHI, PERIYANAINA KESIKA, CHAIYAVAT CHAIYASUT* \\ Innovation Center for Holistic Health, Nutraceuticals, and Cosmeceuticals, Faculty of Pharmacy, Chiang Mai University, Chiang Mai 50200, \\ Thailand \\ Email: chaiyavat@gmail.com
}

Received: 02 Jul 2018, Revised and Accepted: 03 Aug 2018

\begin{abstract}
Aging is the inevitable biological event associated with several physiological, behavioral, and lifestyle events, but people do not wish to become old. The market for anti-aging products is growing gradually, and customers are aware of active principles in the cosmetics. The probiotics are known for several health benefits; especially probiotics regulate the gut health and immune system. Recent studies emphasized the role of probiotics, and probiotic-containing fermented products in cosmetics, and aging. The whole mechanism of aging has not been elucidated yet, but modern aging theories are in two different categories such as programmed theory and damage theory. The aging mechanisms can be discussed in organismal, and cellular level. To some extent, organismal and premature aging is controlled by genetic makeup. Though genetic, and environmental factors impact healthy aging, diet and gut microbiota also play a significant role in senescence. Aging is greatly associated with a diversity of gut microbiota that is often related to the changes in the gastrointestinal tract, and dietary patterns, together with an associated decline in cognitive and immune function, eventually contributing to infirmity. Lactic acid bacteria are reported for the ability to extend the lifespan and/or healthspan. The current manuscript discussed the aging mechanisms, an association of microbiome and aging, and compiled the reported anti-aging properties of probiotics.
\end{abstract}

Keywords: Aging, Anti-aging, Probiotics, Microbiome, Lifespan, Healthspan

(C) 2018 The Authors. Published by Innovare Academic Sciences Pvt Ltd. This is an open access article under the CC BY license (http://creativecommons.org/licenses/by/4.0/) DOI: http://dx.doi.org/10.22159/ijap.2018v10i5.28249

\section{INTRODUCTION}

Aging is the unavoidable biological event, but people do not wish to become old. The market for anti-aging products is growing progressively, and researcher is working on the development of new product or improvisation of the existing product to compete the market competitors. The people are moving towards the effective, safe, natural and chemical free medications and cosmetics. Aging is one of the risk factors for several chronic diseases. The accumulation of disease associated toxic materials like reactive oxygen species (ROS), an excess amount of pro-inflammatory cytokines, can accelerate the aging process The severity of the disease condition and candidate immune players could be the biomarker for the measurement of aging [1]. The healthy aging is closely associated with inflammation and gut microbiome of the host. The high level of proinflammatory cytokines triggers the chronic diseases [2, 3], which in turn disturb the microbiome and aging process that leads to the development of cognitive disorders.

Probiotics are live microbes, which when administered in suitable amounts confer a health benefit on the host The probiotics are known for the positive regulation of gut health and immune regulation. Recent studies emphasized the role of probiotics, and probiotic-containing fermented plant products in cosmetics, and aging [4-6]. Lactobacillus spp. and Bifidobacterium spp. are the commonly used probiotic strain with proven health benefits, [7-9] and those microbes are the commensal microbes present in the human gastrointestinal tract [10]. The probiotic strains were reported to produce enzymes, antagonistic substances like bacteriocin, and neurotransmitters like $\gamma$-aminobutyric acid (GABA) [11-16]

The supplementation of probiotics can decline the harmful microbes like Helicobacter pylori in the gut; thereby it confers the health benefits [17]. The probiotic based treatment for inflammatory bowel diseases and its success rate has been reviewed recently [9].

We have searched the literature in Scopus, PubMed, Google Scholar using the keywords "Probiotic" and "Anti-aging". The literature was selected based on the relevance to the scope of the present manuscript without any filter on publication year. The present study compiled the reported anti-aging effects of probiotics with special emphasis on the role of the microbiome in aging.

\section{Theories, mechanism, and hallmarks of aging}

Several ancient and modern theories were proposed to explain the aging in human. Based on the traditional theories, aging is not genetically programmed. The modern theories of aging have been explained previously [18]. The modern aging theories are in two different categories such as programmed theory and damage theory. As per the programme theory, aging occurs due to the changes in sequential expression of certain genes, hormonal programming, and a programmed decline in immune systems $[19,20]$

According to the damage theory, the body cells were worn out because of being used for many times. During the elder period of life cells were losing their ability to regenerate and eventually leads to the death of the organism. The accumulation of cross-linked proteins, DNA damages, and free radicals harm the cells, which cause aging and death [18].

The complete mechanism of aging has not been elucidated yet. The aging mechanisms can be discussed in organismal, and cellular level. To some extent, organismal and premature aging is controlled by genetic makeup. Klotho, a mouse mutant used for aging research The mutation in klotho gene accelerates the aging. Klotho gene codes for a secreted protein, which has homology to $\beta$-glucosidase of microbes and plants, and also associated with several circulating humoral factors. The mutant showed quite similar symptoms of human aging like lifespan reduction, infertility, reduced physical activity, etc. [21]. The administration of exogenous Klotho protein reverts the aging-related dysfunction of organs in mutant animals, which proved that Klotho plays a critical role in aging, and has been termed as an anti-aging hormone.

The cellular level of aging is greatly hung on the proliferative potential of cells. At every division of normal cells, the telomere, a specific structure of chromosomes of eukaryotic cells, will shorten. The cell division will be arrested after telomers reach a certain size. In the case of stem cells, a specific enzyme called telomerase can prevent or repair the condensed telomeres [22]

The genomic instability, telomere erosion, epigenetic changes, mitochondrial dysfunction, stem cell collapse, cellular senescence, loss or changes in intercellular communication, loss of proteostasis, and dysregulated nutrient sensing are the cumulative explanations for aging [23]. The environmental stressors that disturb the metabolism and inflammation can sturdily affect the lifespan of an organism. The damage to DNA stability may cause errors in DNA replication and generate ROS, which may be the cause of genetic lesions [24]. The epigenetic changes like histone modifications and 
DNA methylation are sensitive to environmental cues that can alter the lifespan [23]. Metabolic changes also have an impact on epigenetic alterations that have been associated with aging [25].

As enlightened, telomeres are predominantly susceptible to agerelated worsening, which is related to the exo-and endogenous, and inflammatory damages [26, 27]. It has been proved that an antiinflammatory diet decelerated the telomere shortening and reduced the cardiovascular risk and mortality [28]. The unbalanced diet and obesity are associated with inflammation-related aging [29].

The involvement of DNA damage, ROS, and inflammation in mitochondrial dysfunction have been reported [30]. The mitochondrial dysfunction is linked with aging and the aging-related symptoms were observed among the patients with mitochondrial diseases [31, 32]. MOTS-c, a mitochondrial-derived peptide, controls the metabolic homeostasis through 5' AMP-activated protein kinase and averts the age-dependent metabolic consequences [33]. MOTS-c supposed to be associated with an increased lifespan of some of the Japanese populations [34].

Protein homeostasis prevents the accumulation of damaged and misfolded protein either by repair or by degrading them [23, 35]. Aging affects the proteostasis, and protein impairment eases the development of age-related diseases [36, 37]. The deterioration of ubiquitin-proteasome and autophagy-lysosomal systems were also associated with aging $[38,39]$. The aging, inflammation and the environmental factors were interconnected and further studies on the aging mechanism and its hallmarks are necessary [1].

\section{Aging and microbiome}

Though genetic, and environmental factors influence healthy aging diet and gut microbiota play an influential role in senescence. Aging is connected to variations in the gut microbiota that are often associated with changes in the gastrointestinal tract, and dietary patterns, together with an associated decline in cognitive and immune function, eventually contributing to frailty. Consequently, dietary pattern helps to restore the microbiota in elderly, which may extend the healthspan of an individual and reduce the frailty [40-42].

The gut microbes of elderly people exhibited low bacterial diversity, changes in the dominant species, reduction in beneficial commensal microbes, and increase in facultative anaerobic bacteria, and a noticeable level of reduction in short-chain fatty acids [43]. Specifically, the level of Firmicutes (Clostridium cluster XIVa and Faecalibacterium prausnitzii, Bifidobacteria spp.) were declined significantly while the Proteobacteria level was increased [44]. The results were not consistent among the population, especially alterations in phylum Bacteroidetes is controversial [40,42, 45, 46]. Likewise, some studies have been reported that lactobacilli were reduced at later stages of life [47] while other studies have been stated oppositely $[46,48]$.

Table 1: Factors that affect the human microbiome at different stages of life

\begin{tabular}{|c|c|c|c|}
\hline Developmental stage & Factor influencing the microbiota & Major group of microbes & Reference \\
\hline Gestation (Pregnancy) & $\begin{array}{l}\text { - Gestational health } \\
\text { - } \text { Diabetes } \\
\text { - } \text { Food habits of the mother } \\
\text { - Use of drugs and antibiotics } \\
\text { - } \quad \text { Microbes in placenta and amniotic fluid } \\
\text { - Hygiene and lifestyle }\end{array}$ & Proteobacteria, Facultative anaerobes & {$[56]$} \\
\hline Parturition & $\begin{array}{l}\text { - } \text { Mode of delivery } \\
\text { - The weight of the baby } \\
\text { - } \quad \text { Hestational age } \\
\text { - The environment of the hospital } \\
\text { - } \quad \text { Length of stay at the hospital } \\
\text { - Hospital microflora } \\
\text { - } \quad \text { Vaginal, fecal, and skin microbiota of mother }\end{array}$ & & \\
\hline Infancy & $\begin{array}{l}\text { - Method of Feeding } \\
\text { - The composition of breast milk/infant formula } \\
\text { - Use of antibiotics and probiotics } \\
\text { - } \text { Weaning } \\
\text { - Pets } \\
\text { - Siblings } \\
\text { Hygiene }\end{array}$ & $\begin{array}{l}\text { Bacteroides, } \\
\text { Bifidobacteria }\end{array}$ & \\
\hline Puberty & $\begin{array}{l}\text { - Food habits } \\
\text { - } \quad \text { Environmental factors } \\
\text { - } \quad \text { The of antibiotics and probiotics } \\
\text { - Use of fermented food } \\
\text { - } \quad \text { Malnutrition } \\
\text { - Infant Illness }\end{array}$ & $\begin{array}{l}\text { Firmicutes, } \\
\text { Bacteroides }\end{array}$ & \\
\hline Adulthood & $\begin{array}{ll}\text { - } & \text { Lifestyle and food habits } \\
\text { - } & \text { Use of antibiotics } \\
\text { - } & \text { Use of prebiotics and probiotics } \\
\text { - } & \text { Sleep } \\
\text { - } & \text { Diseaveling } \\
\text { - } & \text { Pregnancy }\end{array}$ & Bacteroides, Firmicutes & \\
\hline Old age & 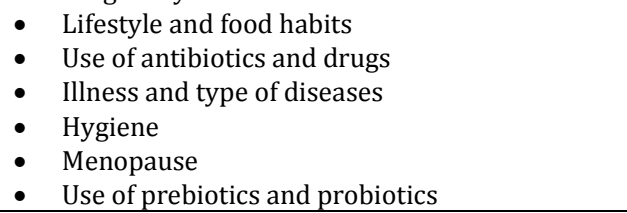 & Obligate and facultative anaerobes & \\
\hline
\end{tabular}


The reduction in microbial metabolic activity was also related to aging-associated diseases like frailty, cognitive decline, decreased appetite, irregular bowel transit, and movement, diabetes, weight loss, arthritis, etc. [49-51]. The gut microbiota greatly influences on host metabolism and nourishment. Some of the microbial metabolites like short-chain fatty acids are absorbed by the host system and help in maintaining the functionality of the organs. Thus, microbial metabolites have a significant role in human health span [52].

The major factors influencing the microbiota of human at every stage of development has been presented in table 1. During the early stage of life, the changes in gut microbiome not necessarily associated with the health conditions of the host system. But the microbiota changes greatly affect the health status and frailty of elderly people [53].

The changes in some microbial group like reduction in F. prausnitzii has negatively associated with frailty while the shift in other microbes was favorable for the host. The microbiota shift is not initiated at any specific stage of life, but the accumulation of minor alteration causes drastic shift and accelerate the aging at later period of life, particularly if the host is physically morbid [54]. Besides, diet and lifestyle are the crucial players in gut microbiota changes, and healthy eating habits prolong the health span of elderly people. The geographical region and ethnicity also have finer contributions to the microbiota changes and frailty [55].

\section{Anti-aging property of probiotics}

The balanced diet and physical activities are associated with increased healthspan and healthy aging. The recent studies revealed that probiotic supplementation can extend the lifespan (table 2).

The lifespan extending ability of centenarian fecal isolate, Lactobacillus salivarius strain FDB89 has been demonstrated using Caenorhabditis elegans. The normal laboratory feed of $C$. elegans was replaced with FDB89 and the total lifespan, SOD (superoxide dismutase) activity, XTT (2, 3-bis-(2-methoxy-4 nitro-5-sulfophenyl) -2H-tetrazolium-5-carboxanilide) reduction capacity, reproduction, pharyngeal pumping, and body size were measured. The results revealed that FDB89 reduced the growth, pharyngeal pumping, and reproducing ability while increased the XTT reduction capacity and SOD activity, and about $11.9 \%$ of lifespan was increased than that of the control. The gradient feeding assay revealed that the dietary restriction extends the lifespan, up to 10 fold, compared to the regular amount of food. The FDB89 supplementation has not changed the lifespan of eat-2 (gene responsible for the pharyngeal action) mutant worms, which indicated that life extension in wild type was the resultant of FDB89 ingestion, and the phenomena depends on the dietaryrestriction [57].

Table 2: The reported anti-aging property of probiotics

\begin{tabular}{|c|c|c|c|c|c|}
\hline S. No. & Model system & Intervention & Duration & Results & References \\
\hline 1 & Caenorhabditis elegans & $\begin{array}{l}\text { Lactobacillus } \\
\text { salivarius FDB89 }\end{array}$ & - & $\begin{array}{l}\text { Extend the lifespan via increasing the antioxidant } \\
\text { mechanism, and associated with dietary restriction }\end{array}$ & [57] \\
\hline 2 & Caenorhabditis elegans & $\begin{array}{l}\text { Bacillus } \\
\text { licheniformis }\end{array}$ & - & $\begin{array}{l}\text { Increased the lifespan of the worms via serotonin } \\
\text { signaling pathway }\end{array}$ & [58] \\
\hline 3 & Caenorhabditis elegans & $\begin{array}{l}\text { Lactobacillus } \\
\text { gasseri SBT } 2055\end{array}$ & - & $\begin{array}{l}\text { Activates the p38MAPK signaling pathway, increased the } \\
\text { expression of } s k n-1 \text {, and amounts of mitochondria. }\end{array}$ & [59] \\
\hline 4 & $\begin{array}{l}\text { Senescence-accelerated } \\
\text { mice }\end{array}$ & $\begin{array}{l}\text { Lactococcus lactis } \\
\text { subsp. cremoris } \mathrm{H} 61\end{array}$ & $2-5$ mo & $\begin{array}{l}\text { Reduced incidence of skin ulcers and hair loss. Increased } \\
\text { the bone density, Reduced the number of Staphylococcus } \\
\text { spp. }\end{array}$ & {$[60]$} \\
\hline 5 & $\begin{array}{l}\text { Senescence-accelerated } \\
\text { mice }\end{array}$ & $\begin{array}{l}\text { Lactococcus lactis } \\
\text { subsp. lactis JCM } \\
5805\end{array}$ & $5 \mathrm{w}$ & $\begin{array}{l}\text { Reduced the effect of senescence and prolong the lifespan } \\
\text { via activating the plasmacytoid dendritic cells. }\end{array}$ & [61] \\
\hline 6 & $\begin{array}{l}\text { Senescence-accelerated } \\
\text { mice strain Prone } \\
1 \text { (SAMP1) and Prone } 10 \\
\text { (SAMP10) }\end{array}$ & $\begin{array}{l}\text { Lactococcus lactis } \\
\text { subsp. lactis strain } \\
\text { Plasma }\end{array}$ & $15-20 w$ & $\begin{array}{l}\text { Increased IFN- } \alpha \text { induction activity, } \\
\text { Reduced the aging-related skin thinning, increased the } \\
\text { expression of tight junction-associated genes, and reduced } \\
\text { the expression muscle degeneration gene. Reduction in } \\
\text { senescence score when compared to respective controls. }\end{array}$ & [62] \\
\hline 6 & Human volunteers & $\begin{array}{l}\text { Lactobacillus } \\
\text { plantarum HY7714 }\end{array}$ & $12 \mathrm{w}$ & $\begin{array}{l}\text { Reduced the skin wrinkle depth, improved the skin gloss, } \\
\text { and moisture content. Significant improvement in skin } \\
\text { elasticity. }\end{array}$ & [63] \\
\hline
\end{tabular}

The wild type and mutant strains of $C$. elegans were fed with Bacillus licheniformis (Korean fermented food isolate) or Escherichia coli OP50 or Lactobacillus rhamnosus GG and validated the lifespan extension, and its mechanism was validated. B. licheniformis extended the lifespan of $C$. elegans up to $45 \%$ when compared with OP50 control. The nematode intestinal colonizing ability of $B$. licheniformis was lower than L. rhamnosus and 0P50. The experiments with mutant strains, ser-1, and ser-7 (serotonin receptor gene), tph-1 (tryptophan hydroxylase), mod-1 (serotoningated chloride channel), bas-1 (serotonin-and dopamine-synthetic aromatic amino acid decarboxylase), revealed that $B$. licheniformis has an impact on serotonin signaling system. The lifespan extension was mediated by the serotonin signaling [58].

Lactobacillus gasseri SBT2055 mediated lifespan extension of $C$. elegans, and the mechanism behind the longevity has been reported. L. gasseri SBT2055-fed worms showed about 37\% of lifespan extension when compared with control. The up-regulation of skin-1 (transcription factor orthologs to Nuclear factor-erythroid-related factor of mammalian, and involved in oxidative stress regulation, antioxidant defense responses), and SKN-1 regulating genes were observed in L. gasseri SBT2055-fed worms. L. gasseri SBT2055 increased the amounts of mitochondria, stimulated the SKN-1 by p38 MAPK signaling pathway thereby activate the phase II detoxification system. The results suggested that L. gasseri SBT2055 prolonged the lifespan of $C$. elegans via improving the antioxidant system and activating the innate immune system through $\mathrm{SKN}-1$, and p38 MAPK signaling pathway [59].

The senescence-accelerated mice (SAM) were supplemented with heat-killed $(0.05 \%$ along with laboratory diet) or fermented milk product $\left(10^{8} \mathrm{CFU}\right.$ per $\mathrm{ml}$ of H61) containing Lactococcus lactis subsp. cremoris $\mathrm{H} 61$ from age one or nine months to age three or fourteen months. Another set of SAM was administered with $2 \times 10^{7}$ cells/mouse/2-3 d from the age of eight months to twelve months. Then the animals were monitored for the physiological, micro biota, immune, and antioxidant changes. The results suggested that the consumption of heat-killed $\mathrm{H} 61$ reduce the loss of bone density, hair loss, and manifestation of skin ulcers. The level of IL-12, INF- $\gamma$ was increased upon H61 intervention when compared with control. The lipid peroxidation was hindered in experimental rats fed with H61. The microbiota analysis revealed that H61 supplementation does not affect the Enterococcus spp., Bacteroides spp., and Bifidobacterium spp. content while the reduction in Staphylococcus spp. was observed. The supplementation of fermented milk and live cells of H61 also exhibited the same impact in the SAM. Collectively, the results of the study suggested that H61 could be a potent probiotic for the suppression or delaying of aging-related 
consequences [60]. Recently, Sugimura et al. [61] reported the lifeextending property of another L. lactis strain, namely L. lactis subsp. lactis JCM 5805 using SAM model. The SAM was fed with $1 \mathrm{mg}$ of heat-killed JCM5805/day from the age of seven weeks to twelve weeks and monitored the changes until the age of $82 \mathrm{w}$. The results proposed that the administration of JCM5805 reduced the pathological consequences in lungs and liver, the incidence of hepatocellular foci alterations in the probiotic-treated group when compared with control. The mRNA level of $I L-1 \beta$ was lesser in JCM5805-treated mice. The aging-related skin is thinning and mass muscle decline was reduced upon JCM5805 intervention. The plasmacytoid dendritic cells were stimulated in JCM5805 supplemented mice compared to control. Together, the study suggested that long-term supplementation of JCM5805 may extend the lifespan [61]. The supplementation of Lactococcus lactis subsp. lactis strain Plasma to senescence-accelerated mice strains Prone 1 (SAMP1) and Prone 10 (SAMP10) activated the IFN- $\alpha$ induction activity in SAMP1, and reduced the aging-related skin thinning, improved the naïve $\mathrm{T}$ cell ratio, increased the expression of tight junction-related genes (Claudin-1 and Zo-1), and suppressed the expression of muscle degeneration gene (FoxO-1) in SAMP10. Overall, the senescence score was reduced in the probiotic-supplemented group when compared with the respective controls [62].

Lee et al. [60] reported the anti-skin aging properties of Lactobacillus plantarum HY7714 in humans. The human volunteers with dry skin and skin wrinkles (41-59 y old) were supplemented with L. plantarum HY7714 (1010 CFU/day) or placebo for twelve weeks. The probiotic supplementation reduced the skin wrinkle, dehydration, and increased the skin gloss, and skin elasticity after twelve weeks compared to baseline and control. The study primarily stated the anti-skin aging property of $L$. plantarum HY7714 in humans [63].

\section{CONCLUSION}

Aging is associated with several complicated biological, environmental, geographical, behavioral processes, and also the strongest risk factor for several chronic diseases. The scientific reports revealed that the gut microbiota plays a critical role in maintaining the host immune system, antioxidant system, cognition, etc. The microbiome of individuals depends on several life habits from the gestation (table 1). The dietary factors greatly influence the longevity and mortality. It is known that the probiotics supplementation significantly affects the gut microbiota. Even though some studies described the anti-aging properties of probiotics, the reports on clinical trials are very limited. The mechanism of probiotic mediated longevity has not been demonstrated completely. The extensive research on the association of probiotics-microbiota-longevity may help to extend the healthspan and life expectancy of humans.

\section{ACKNOWLEDGMENT}

Bhagavathi Sundaram Sivamaruthi gratefully acknowledges the CMU Post-Doctoral Fellowship (Ref: No. 6592(11)/1379, dated 26 February 2018), and Faculty of Pharmacy, Chiang Mai University for the support.

\section{AUTHORS CONTRIBUTIONS}

BSS and PK contributed to conception and design, acquisition, manuscript preparation, and critical revision of the manuscript. CC involved in the review and finalization of the manuscript. All the authors agree with the content of the manuscript.

\section{CONFLICT OF INTERESTS}

The authors declare that there is no conflict of interests

\section{REFERENCES}

1. Bektas A, Schurman SH, Sen R, Ferrucci L. Aging, inflammation and the environment. Exp Gerontol 2018;105:10-8.

2. Fabbri E, An Y, Zoli M, Simonsick EM, Guralnik JM, Bandinelli S, et al. Aging and the burden of multimorbidity: associations with inflammatory and anabolic hormonal biomarkers. J Gerontol A Biol Sci Med Sci 2015;70:63-70.
3. Stepanova M, Rodriguez E, Birerdinc A, Baranova A. Ageindependent rise of inflammatory scores may contribute to accelerated aging in multi-morbidity. Oncotarget 2015;6:1414-21.

4. Sirilun S, Sivamaruthi BS, Kumar N, Kesika P, Peerajan S, Chaiyasut C. Lactobacillus-fermented plant juice as a potential ingredient in cosmetics: Formulation and assessment of natural mouthwash. Asian J Pharm Clin Res 2016;9(Suppl 3):52-6.

5. Sharma D, Kober MM, Bowe WP. Anti-aging effects of probiotics. J Drugs Dermatol 2016;15:9-12.

6. Sivamaruthi BS, Chaiyasut C, Kesika P. Cosmeceutical importance of fermented plant extracts: a short review. Int J Appl Pharm 2018;10:31-4.

7. Sirilun S, Chaiyasut C, Kesika P, Peerajan S, Sivamaruthi BS. Screening of lactic acid bacteria with the immune modulating property, and the production of lactic acid bacteria mediated fermented soymilk. Natl J Physiol Pharm Pharmacol 2017;7:1397405.

8. Chaiyasut C, Woraharn S, Sivamaruthi BS, Kesika P, Lailerd N, Peerajan S. Lactobacillus fermentum HP3 mediated fermented Hericium erinaceus juice as a health-promoting food supplement to manage diabetes mellitus. J Evid Based Integr Med 2018;23:1-9.

9. Sivamaruthi BS. A comprehensive review on clinical outcome of probiotic and synbiotic therapy for inflammatory bowel diseases. Asian Pac J Trop Biomed 2018;8:179-86.

10. Reuter G. The Lactobacillus and Bifidobacterium microflora of the human intestine: composition and succession. Curr Issues Int Microbiol 2001;2:43-53.

11. Woraharn S, Lailerd N, Sivamaruthi BS, Wangcharoen W, Sirisattha $\mathrm{S}$, Chaiyasut C. Screening and kinetics of glutaminase and glutamate decarboxylase producing lactic acid bacteria from fermented thai foods. Food Sci Technol Campinas 2014;34:793-9.

12. Park S, Lee J, Lim S. The probiotic characteristics and GABA production of Lactobacillus plantarum K154 isolated from kimchi. Food Sci Biotechnol 2014;23:1951-7.

13. Wang Y, Sun Y, Zhang X, Zhang Z, Song J, Gui M, et al. Bacteriocinproducing probiotics enhance the safety and functionality of sturgeon sausage. Food Control 2015;50:729-35.

14. Woraharn S, Lailerd N, Sivamaruthi BS, Wangcharoen W, Peerajan S, Sirisattha S, et al. Development of fermented Hericium erinaceus juice with high content of L-glutamine and L-glutamic acid. Int J Food Sci Technol 2015;50:2104-12.

15. Bharti V, Mehta A, Singh S, Jain N, Ahirwal L, Mehta S. Bacteriocin: a novel approach for preservation of food. Int J Pharm Pharm Sci 2015;7:20-9.

16. Mohanty D, Saini MR, Mohapatra S. In vitro study on release of bioactive antimicrobial compounds from dairy products by certain promising probiotic lactobacillus strains. Int J Pharm Pharm Sci 2017;9:27-31

17. Varankovich NV, Nickerson MT, Korber DR. Probiotic-based strategies for therapeutic and prophylactic use against multiple gastrointestinal diseases. Front Microbiol 2015;6:685.

18. Jin K. Modern biological theories of aging. Aging Dis 2010;1:72-4

19. Davidovic M, Sevo G, Svorcan P, Milosevic DP, Despotovic N, Erceg P. Old age as a privilege of the "selfish ones". Aging Dis 2010;1:139-46.

20. Van Heemst D. Insulin, IGF-1 and longevity. Aging Dis 2010;1:147-57.

21. Kuro-o M, Matsumura Y, Aizawa H, Kawaguchi H, Suga T, Utsugi $\mathrm{T}$, et al. Mutation of the mouse klotho gene leads to a syndrome resembling ageing. Nature 1997;390:45-51.

22. Takahashi Y, Kuro-o M, Ishikawa F. Aging mechanisms. Proc Natl Acad Sci USA 2000;97:12407-8.

23. Lopez Otin C, Blasco MA, Partridge L, Serrano M, Kroemer G. The hallmarks of aging. Cell 2013;153:1194-217.

24. Hoeijmakers JH. DNA damage, aging, and cancer. N Engl J Med 2009;361:1475-85.

25. Lopez Otin C, Galluzzi L, Freije JMP, Madeo F, Kroemer G. Metabolic control of longevity. Cell 2016;166:802-21.

26. Blackburn EH, Greider CW, Szostak JW. Telomeres and telomerase: the path from maize, Tetrahymena and yeast to human cancer and aging. Nat Med 2006;12:1133-8.

27. Jurk D, Wilson C, Passos JF, Oakley F, Correia Melo C, Greaves L, et al. Chronic inflammation induces telomere dysfunction and accelerates ageing in mice. Nat Commun 2014;2:4172. 
28. Garcia Calzon S, Zalba G, Ruiz Canela M, Shivappa N, Hebert JR, Martinez JA, et al. Dietary inflammatory index and telomere length in subjects with a high cardiovascular disease risk from the PREDIMED-NAVARRA study: cross-sectional and longitudinal analyses over 5 y. Am J Clin Nutr 2015;102:897-904.

29. Schrager MA, Metter EJ, Simonsick E, Ble A, Bandinelli S, Lauretani $\mathrm{F}$, et al. Sarcopenic obesity and inflammation in the InCHIANTI study. J Appl Physiol 2007;102:919-25.

30. Faria A, Persaud SJ. Cardiac oxidative stress in diabetes: mechanisms and therapeutic potential. Pharmacol Ther 2017;172:50-62.

31. Wang Y, Hekimi S. Mitochondrial dysfunction and longevity in animals: untangling the knot. Science 2015;350:1204-7.

32. DiMauro S, Schon EA, Carelli V, Hirano M. The clinical maze of mitochondrial neurology. Nat Rev Neurol 2013;9:429-44.

33. Lee C, Zeng J, Drew BG, Sallam T, Martin-Montalvo A, Wan J, et al. The mitochondrial-derived peptide MOTS-c promotes metabolic homeostasis and reduces obesity and insulin resistance. Cell Metab 2015;21:443-54.

34. Fuku N, Pareja Galeano H, Zempo H, Alis R, Arai Y, Lucia A, et al. The mitochondrial-derived peptide MOTS-c: a player in exceptional longevity. Aging Cell 2015;14:921-3.

35. Sala AJ, Bott LC, Morimoto RI. Shaping proteostasis at the cellular, tissue, and organismal level. J Cell Biol 2017;216:1231-41.

36. Koga H, Kaushik S, Cuervo AM. Protein homeostasis and aging: the importance of exquisite quality control. Ageing Res Rev 2011;10:205-15.

37. Powers ET, Morimoto RI, Dillin A, Kelly JW, Balch WE. Biological and chemical approaches to diseases of proteostasis deficiency. Annu Rev Biochem 2009;78:959-91.

38. Rubinsztein DC, Marino G, Kroemer G. Autophagy and aging. Cell 2011;146:682-95.

39. Tomaru U, Takahashi S, Ishizu A, Miyatake Y, Gohda A, Suzuki S et al. Decreased proteasomal activity causes age-related phenotypes and promotes the development of metabolic abnormalities. Am J Pathol 2012;180:963-72.

40. Claesson MJ, Cusack S, O’Sullivan O, Greene-Diniz R, de Weerd $\mathrm{H}$, Flannery E, et al. Composition, variability, and temporal stability of the intestinal microbiota of the elderly. Proc Natl Acad Sci USA 2011;108(Suppl 1):4586-91.

41. Claesson MJ, Jeffery IB, Conde S, Power SE, O'Connor EM, Cusack S, et al. Gut microbiota composition correlates with diet and health in the elderly. Nature 2012;488:178-84.

42. Odamaki T, Kato K, Sugahara H, Hashikura N, Takahashi S, Xiao $\mathrm{JZ}$, et al. Age-related changes in gut microbiota composition from newborn to centenarian: a cross-sectional study. BMC Microbiol 2016;16:90.

43. Salazar N, Arboleya S, Valdes L, Stanton C, Ross P, Ruiz L, et al. The human intestinal microbiome at extreme ages of life. Dietary intervention as a way to counteract alterations. Front Genet 2014;5:406.

44. Salazar N, Valdes Varela L, Gonzalez S, Gueimonde M, de Los Reyes Gavilan CG. Nutrition and the gut microbiome in the elderly. Gut Microbes 2017;8:82-97.

45. Salazar N, Lopez P, Valdes L, Margolles A, Suarez A, Patterson $\mathrm{AM}$, et al. Microbial targets for the development of functional foods accordingly with nutritional and immune parameters altered in the elderly. J Am Coll Nutr 2013;32:399-406.
46. Tiihonen $\mathrm{K}$, Ouwehand $\mathrm{AC}$, Rautonen N. Human intestinal microbiota and healthy ageing. Ageing Res Rev 2010;9:107-16.

47. Woodmansey EJ. Intestinal bacteria and ageing. J Appl Microbiol 2007;102:1178-86.

48. Makivuokko H, Tiihonen K, Tynkkynen S, Paulin L, Rautonen N. The effect of age and non-steroidal anti-inflammatory drugs on human intestinal microbiota composition. Br J Nutr 2010;103:227-34.

49. Rampelli S, Candela M, Turroni S, Biagi E, Collino S, Franceschi $\mathrm{C}$, et al. Functional metagenomic profiling of intestinal microbiome in extreme ageing. Aging 2013;5:902-12.

50. Ursell LK, Haiser HJ, Van Treuren W, Garg N, Reddivari L, Vanamala $\mathrm{J}$, et al. The intestinal metabolome: an intersection between microbiota and host. Gastroenterology 2014;146:1470-6.

51. Rios Covian D, Ruas Madiedo P, Margolles A, Gueimonde M, de Los Reyes Gavilan CG, Salazar N. Intestinal short chain fatty acids and their link with diet and human health. Front Microbiol 2016;7:185.

52. Nicholson JK, Holmes E, Kinross J, Burcelin R, Gibson G, Jia W, et al. Host-gut microbiota metabolic interactions. Science 2012;336:1262-7.

53. Jackson MA, Jeffery IB, Beaumont M, Bell JT, Clark AG, Ley RE, et al. Signatures of early frailty in the gut microbiota. Genome Med 2016;8:8.

54. O'Toole PW, Jeffery IB. Gut microbiota and aging. Science 2015;350:1214-5.

55. Mueller S, Saunier K, Hanisch C, Norin E, Alm L, Midtvedt T, et al. Differences in fecal microbiota in different European study populations in relation to age, gender, and country: a crosssectional study. Appl Environ Microbiol 2006;72:1027-33.

56. Nagpal R, Mainali R, Ahmadi S, Wang S, Singh R, Kavanagh K, et al. Gut microbiome and aging: physiological and mechanistic insights. Nutr Health Aging 2018;4:267-85.

57. Zhao Y, Zhao L, Zheng X, Fu T, Guo H, Ren F. Lactobacillus salivarius strain FDB89 induced longevity in Caenorhabditis elegans by dietary restriction. J Microbiol 2013;51:183-8.

58. Park MR, Oh S, Son SJ, Park DJ, Oh S, Kim SH, et al. Bacillus licheniformis isolated from traditional Korean food resources enhances the longevity of Caenorhabditis elegans through serotonin signaling. J Agric Food Chem 2015;63:10227-33.

59. Nakagawa H, Shiozaki T, Kobatake E, Hosoya T, Moriya T, Sakai $\mathrm{F}$, et al. Effects and mechanisms of prolongevity induced by Lactobacillus gasseri SBT2055 in Caenorhabditis elegans. Aging Cell 2016;15:227-36.

60. Kimoto Nira H, Suzuki C, Kobayashi M, Sasaki K, Kurisaki J, Mizumachi K. Anti-ageing effect of a Lactococcal strain: analysis using senescence-accelerated mice. Br J Nutr 2007;98:1178-86.

61. Sugimura T, Jounai K, Ohshio K, Suzuki H, Kirisako T, Sugihara $\mathrm{Y}$, et al. Long-term administration of pDC-stimulative Lactococcus lactis strain decelerates senescence and prolongs the lifespan of mice. Int Immunopharmacol 2018;58:166-72.

62. Tsuji R, Komano Y, Ohshio K, Ishii N, Kanauchi O. Long-term administration of pDCstimulative lactic acid bacteria, lactococcus lactis strain plasma, prevents immune-senescence and decelerates individual senescence. Exp Gerontol 2018;111:10-6.

63. Lee DE, Huh CS, Ra J, Choi ID, Jeong JW, Kim SH, et al. Clinical evidence of effects of Lactobacillus plantarum HY7714 on skin aging: a randomized, double blind, placebo-controlled study. J Microbiol Biotechnol 2015;25:2160-8. 